\title{
Food Supply Chain Management using Block chain in Food Traceability
}

\author{
Sudha Mercy S, Abinaya P, Kanimozhi J, Shree Rohini I.
}

\begin{abstract}
A blockchain enlivened web of-things design for making a straightforward food flexibly chain. The engineering utilizes a proof-of-object based validation convention, which is undifferentiated from the cryptographic money's evidence of-work convention. This design is acknowledged by utilizing a RFID based sensor at the client level and blockchain at digital layer. The RFID gives a one of a kind character of the item and the sensor information, which helps continuously observing of value. So a little element size $900 \mathrm{MHz}$ RFID coupled sensor was $\neg$-developed and signified for continuous sensor information securing. The blockchain engineering helps in making a solid computerized database of the food bundles at each case. A total security investigation was performed to investigate the defenselessness of the proposed engineering under various sorts of cyberattacks.
\end{abstract}

Key: Food supply chain, Crypto-currency, RFID sensor, Block Chain.

\section{INTRODUCTION}

A blockchain enlivened web of-things design for making a straightforward food flexibly chain. The engineering utilizes a proof-of-object based validation convention, which is undifferentiated from the cryptographic money's evidence of-work convention. This design is acknowledged by utilizing a RFID based sensor at the client level and blockchain at digital layer. The RFID gives a one of a kind character of the item and the sensor information, which helps continuously observing of value. So a little element size $900 \mathrm{MHz}$ RFID coupled sensor was - ᄀ-developed and signified for continuous sensor information securing. The blockchain engineering helps in making a solid computerized database review criteria.

Revised Manuscript Received on June 10, 2020.

* Correspondence Author

Ms. Sudha Mercy. S*, Assistant Professor, Department of Computer Science and Engineering, Jeppiaar Institute of Technology, Sriperumbudur, Tamil Nadu, India. E-mail: sudhamercy@gmail.com

Abinaya. P, Student, Department of Computer Science and Engineering, Jeppiaar Institute of Technology, Sriperumbudur, Tamil Nadu, India. E-mail: abinaya21298@gmail.com

Kanimozhi. J, Student, Department of Computer Science and Engineering, Jeppiaar Institute of Technology, Sriperumbudur, Tamil Nadu, India. E-mail: kani22fruit@mail.com

Shree Rohini. I, Student, Department of Computer Science and Engineering, Jeppiaar Institute of Technology, Sriperumbudur, Tamil Nadu, India. E-mail: shreerohini98@mail.com

(C) The Authors. Published by Blue Eyes Intelligence Engineering and Sciences Publication (BEIESP). This is an open access article under the CC BY-NC-ND license (http://creativecommons.org/licenses/by-nc-nd/4.0/)

\section{LITERATURE SURVEY}

Shay Gueron, Jesse Walker, Simon Johnson technique presents the cryptographic hash capacity to figure a SHA-512 than it is to register a SHA-256 over a given size of information and on the off chance that you are utilizing a hexadecimal portrayal, every digit codes for 4 bits and the rise of unavoidable 64 piece and (pointer size) processing we see that it is more savvy We propose a degree of value or accomplishment approach to utilize SHA-512 and shorten its yield to 256 bits. For 64 piece structures, CPU and ALU designs are those that depend on registers, this would yield a progressively productive 256 piece hashing calculation, than the current SHA-256. We call this strategy SHA-512/256. A few digital forms of money like Bitcoin use SHA-256 for checking exchanges and figuring evidence of work or verification of part of fence. We likewise give a strategy to lessening the size of the SHA-512 constants table that a usage should store. Xiaofeng Lu, Zhaowei Qu, ,Qi Li Container Hui says a great deal of security insurance advancements have been proposed, however the vast majority of them are autonomous and doen not have some particular protection. And also, there is not really enough detail inspection into the respect something brought about by security. After particular thing happened, this paper centers around the nature of the protection data and proposes a overall aim to group the security level of the authorized data. Protective measures are arranged into three security levels and each level has its different security objective individually. In view of the large information from the web index, we can order the security levels of 52 diverse protection things. The Baidu internet searcher is taken as the exploration base foundation of gathering related useful information. Mahmoud Ammar, Giovanni Russello, Bruno Crispo presents the Web of Things (IOT) is vigorously influencing, , running from feel sorry for wear-capable gadgets to enormous modern frameworks and diverting our day by day lives in numerous areas. Because of, a broad miscellanous collection of thing of IOT applications have been created and conveyed effect use of different IoT base structures. An IoT structure is a lot of controlling principles, supporting programming, conventions, and measures which streamline the execution of IoT applications. The achievement of these applications basically relies upon the biological system qualities of the IoT structure, the cutting edge is finding a path between adapting your information and where issues identified with security are significant, ensuring protection. For every structure, the fundamentals of growing outsider brilliant applications, the perfect equipment, and the security highlights. Looking at approving structures shows that the equivalent regular measures utilized for approving correspondences,

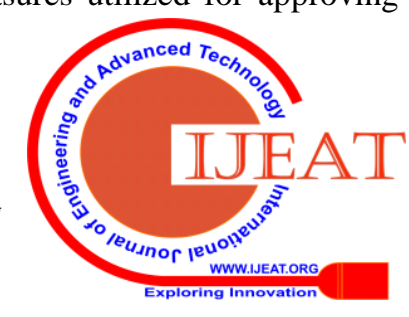




\section{Food Supply Chain Management using Block chain in Food Traceability}

though different procedures followed for giving other security properties. In this paper, an aggregate of 8 structures are considered in framework ,we overview the security of the fundamental IoT systems.

\section{EXISTING SYSTEM}

In existing framework, package date, expiry date and, bundle date and so on.. Along these lines, the end client or client doesn't have any attention to that item subtleties. That item have item id and shop data as it were. Ongoing checking of the food perspective and perceivability of that quality list would forestall flare-up of food-borne sicknesses, monetarily inspired defilement, sullying, food wastage because of feeling that inaccurate on the grounds that dependent on broken thinking about the named expiry dates, and misfortunes because of decay, which impactsly affect the food security.

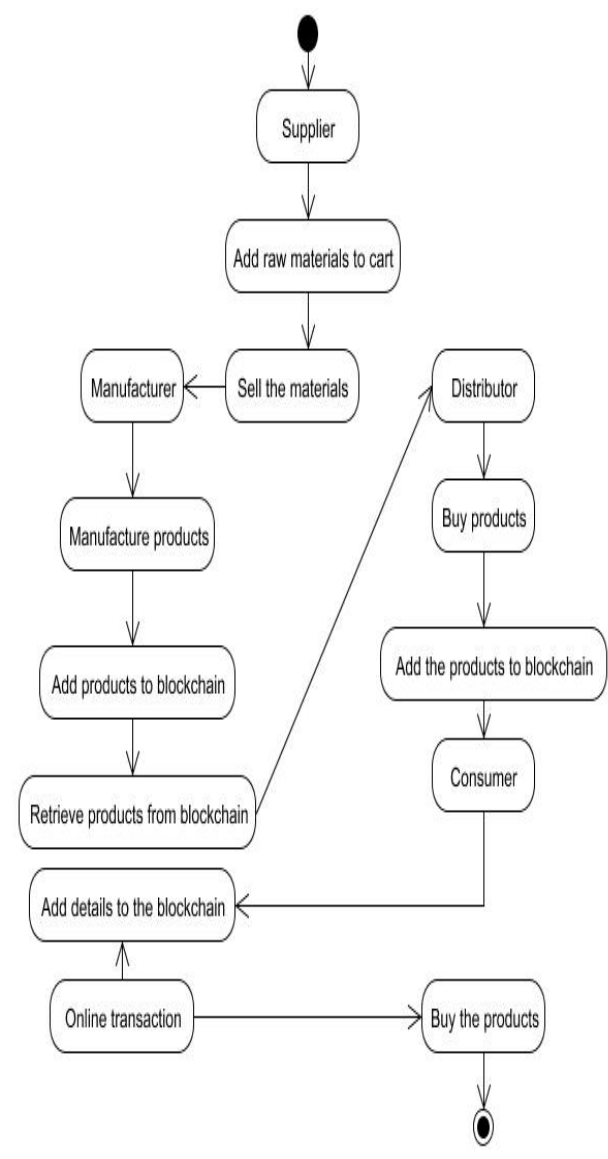

\section{PROPOSED SYSTEM}

So as to build wellbeing and forestall wastage, present day IoT based innovations are needed to screen the food quality and increment the eye shot degree of the checked information. Detecting strategies steady with existing following and following framework are attentively for quite a while for observing food items. These sensors can be non-obtrusive or intrusive in observing the physical or concoction properties of food all in all, these sensors are meant to keep inadequate items from arriving at the shoppers. We should include the every single required detail in square chain, Similar to item purchasing spot and item fixings, purchasing date, date, item bundling date and so on. Furthermore, most significant we should utilize QR code Scanner remote sensor for examine the item and make sensor ID. Each bundled food item with an inserted sensor ID goes through various phases of exchanges at various terminals beginning from bundling through transportation, stockpiling lastly to a buyer for procurement. When the exchange is confirmed, the exchange of the sensor ID is changed over into a square of data and attached to its previous information squares therefore framing a chain of data squares and in this way a square chain. . An information square is made containing the data about the bundle at each substantial exchange.

\section{BLOCK CHAIN}

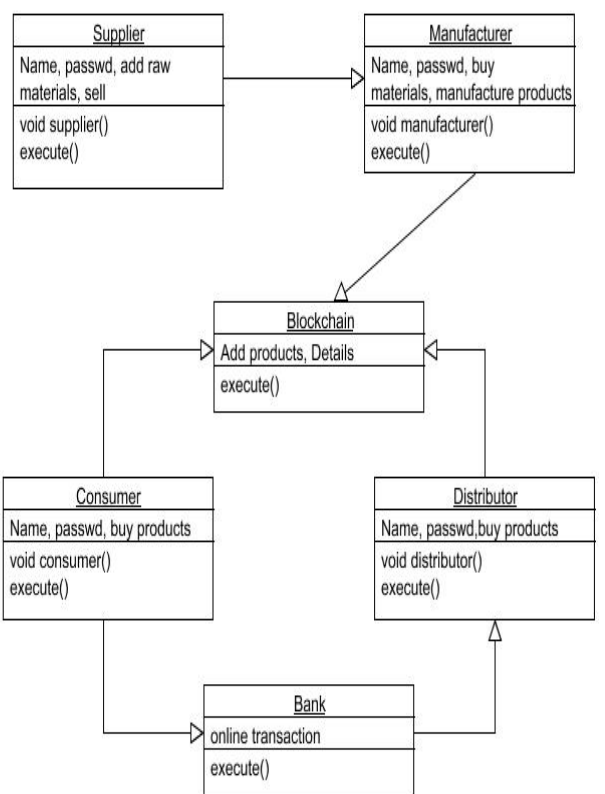

Square chain innovation was proposed to improve the discernibility of a food item along the gracefully chain utilizing diverse IoT-based innovation, for example, remote sensor arrange (WSN), Worldwide situating Framework (GPS), and RFID. Notwithstanding, expansion of a solitary square in existing blockchain needs to experience broad calculation expending parcel of power. A blockchain is an miscellaneous collection of four right angle, where each square contains a hash of the past four right angle producing a chain of squares. The first difficult in the blockchain is known as the starting square from which the blockchain starts growing up to the latest square. The exchanges are mined into a square by excavators before including it into block chain. Singular squares must contain a Paw showing agreement among the hubs about the legitimacy of the exchanges.

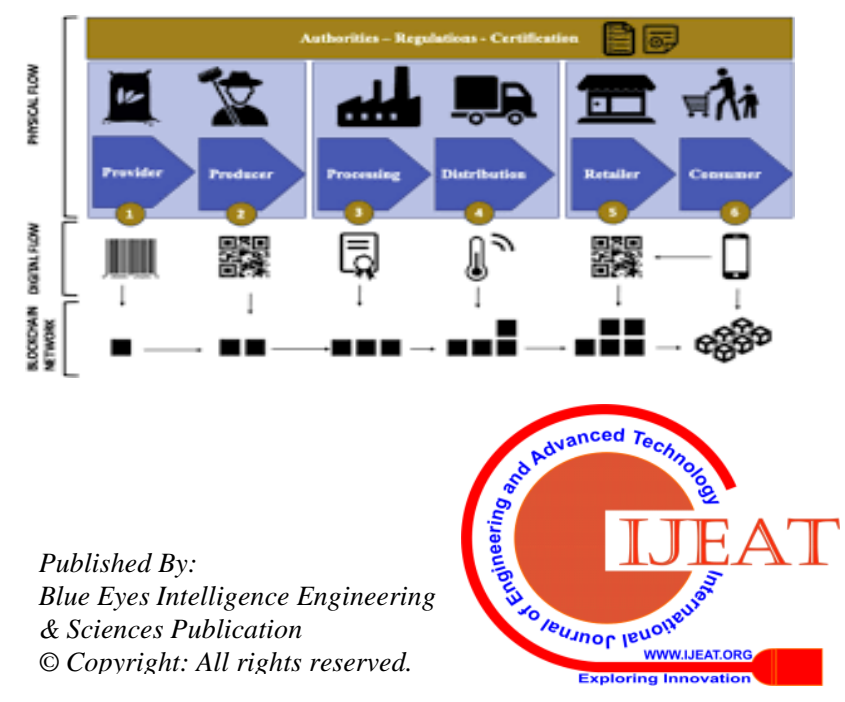


Square chain innovation was proposed to improve the discernibility of a food item along the gracefully chain utilizing diverse IoT-based innovation, for example, remote sensor arrange (WSN), Worldwide situating Framework (GPS), and RFID. Notwithstanding, expansion of a solitary square in existing blockchain needs to experience broad calculation expending parcel of power. A blockchain is an miscellaneous collection of four right angle, where each square contains a hash of the past four right angle producing a chain of squares. The first difficult in the blockchain is known as the starting square from which the blockchain starts growing up to the latest square. The exchanges are mined into a square by excavators before including it into blockchain. Singular squares must contain a Paw showing agreement among the hubs about the legitimacy of the exchanges.

\section{WORKING METHOD}

The sensor with the RFID is known as a "sensor ID." The sensor ID might be a detached or a functioning sort or a solitary sensor or numerous sensor type. The regular system shared by all the terminals is named as "shared system." When an exchange is approved dependent on the agreement of taking an interest terminals, the exchange is changed over into a "square" and remembered for the blockchain. Aside from terminals, there exists another kind of hub, a "chief," that is answerable for arrangement making, The sweep of a sensor ID by a terminal and enrolling the information is named as an "exchange" and preparing demands dependent on agreement with different hubs. The information gathering and handling hub, that checks a sensor ID is named as a "terminal".

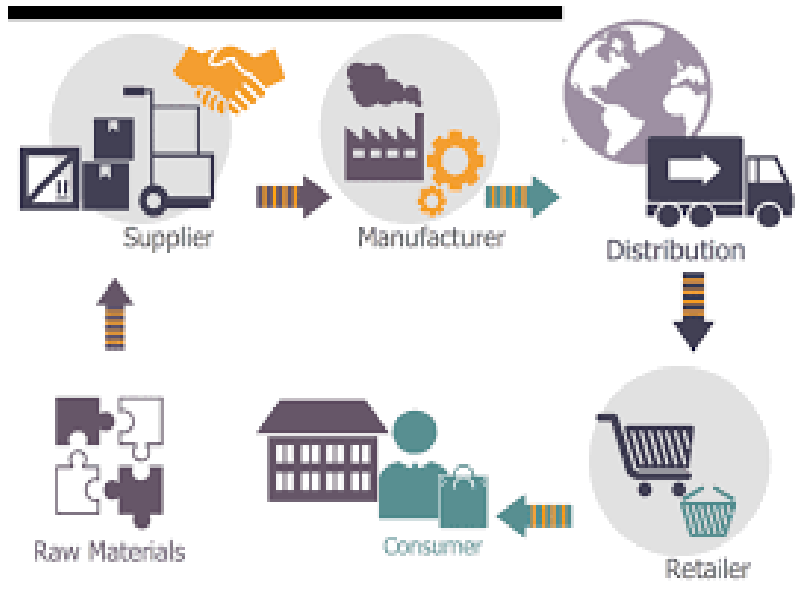

Finally, there exists a third type of node called "agent," that requests information about a Sensor ID from the square chain by giving an appropriate digital location. . An information square will be made containing the whole insights concerning the bundle at each legitimate exchange. When all exchanges are verified, the exchange of the sensor ID is changed over into a square of data and added to its previous information squares hence shaping a chain of data squares and consequently a square chain. Each bundled food item with a sensor ID goes through various phases of exchanges beginning from bundling with transportation, stockpiling and finally to a customer .

Data storage: The block chain data is stored individually and whenever a new block is added, it gets updated to all the nodes present. Apart from the commonly shared block chain data, each of the terminal have their own private data, which mainly contains the physical RFID address. Whenever there is a transaction it will be sent as a request which is received by the other terminal, followed by hashing all the locally stored physical addresses in order to and a match of the requested cyber address.

Transaction Information: At whatever point we register a sensor ID ,it gets filtered by all the terminals in following phases of the Food Supply Chain. When Transaction is communicated, every terminal assesses the exchange. Presently, every terminal verifies if an exchange on the specific sensor ID was performed before. If there should arise an occurrence of a matches ,implies that the sensor ID was filtered before at the terminal . The affirmation is then sent over the system which will be assists with keeping the data of the item forward-thinking and forestall presentation of any items in the FSC(Forest stewardship committee) other than items furnished with one of a kind sensor ID with affirmation with computationally light weight.

Analyzing the barcode number based on API: For every item it contains the standardized tag number and its number will be going through food API then fixings will be taken out by utilizing scanner tag number. In the food flexibly chain ,there will be for the most part four individuals included to be specific the Supplier ,the Distributor, the maker and the Consumer. The Supplier is answerable for providing the fundamental crude materials to build up the item. The provider first logins and gives the whole insights regarding the crude materials they produce and furthermore about themselves. The exchanges gets put away in the square chain. At whatever point maker needs crude materials solicitation will be sent to the provider, who will acknowledge it.

Manufacture sends product details to Block chain: The maker at first makes the record. This outcomes in duplicating of food items. They will break down the crude materials and the maker will demand the amount of crude materials to the provider. The assembling will send the item ID, number of bundles, expiry date and so on,. to the square chain and afterward the made item will be added to maker shipment. At that point providers will acknowledge the solicitation from maker and crude material will be added to the producer stock. From the square chain the producer will recover the item.
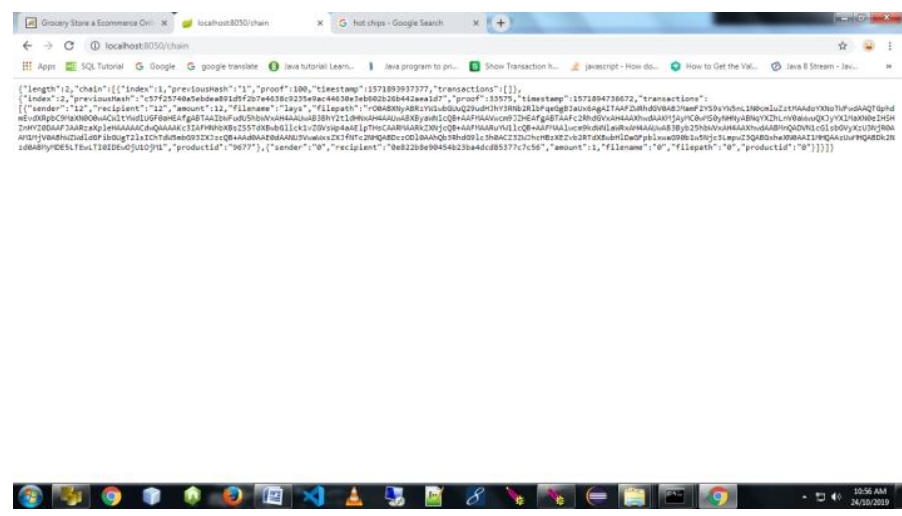

Published By:

Blue Eyes Intelligence Engineering \& Sciences Publication

(C) Copyriaht: All rights reserved.

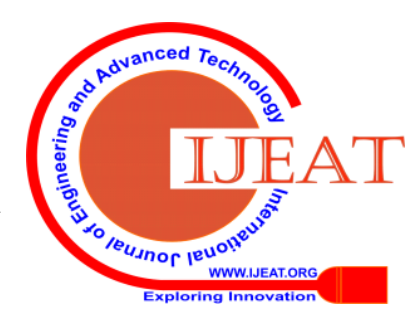




\section{Food Supply Chain Management using Block chain in Food Traceability}

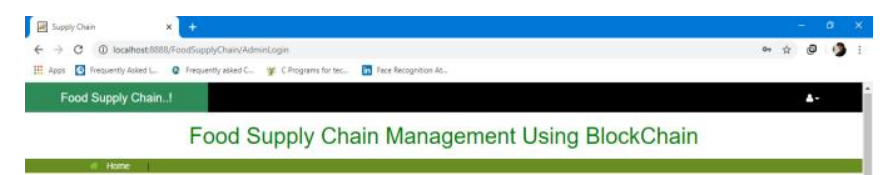

Distributer purchasing the product: When the solicitation has been acknowledged ,the exchange would occur between the terminals over the system and the square chain would be refreshed with the subtleties. The distributer will enroll himself with his subtleties. The distributer will be seeing the item in the producer truck and sends the solicitation to the maker.

\section{Food Supply Chain.l}

\section{$\sqrt{1 \cdot}$}

\section{Supply Chain Management Using BlockChain}

\begin{tabular}{|c|c|c|c|c|c|c|c|c|c|}
\hline A Hane & \multicolumn{9}{|c|}{ Wecont by } \\
\hline \multicolumn{10}{|l|}{ WENTORY } \\
\hline LOOS SUPOUER & \multicolumn{9}{|c|}{ DISTRIBUTOR REQUEST...! } \\
\hline \multicolumn{10}{|l|}{ aOD procouct } \\
\hline 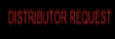 & 50 & Dethaun il & Pinath & Mata Nat & Pito & Raders & Date fint & $\operatorname{lat}$ & Satus \\
\hline SHDENT & \multirow[t]{2}{*}{1} & \multirow[t]{2}{*}{ DSFTROWS } & \multirow[t]{2}{*}{66} & \multirow[t]{2}{*}{ إنها } & \multirow[t]{2}{*}{10} & \multirow[t]{2}{*}{3} & \multirow[t]{2}{*}{ 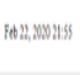 } & \multirow{2}{*}{8} & \multirow[t]{2}{*}{ dowent } \\
\hline TRACE & & & & & & & & & \\
\hline
\end{tabular}

QR scan code verification \& bank interfacing: At whatever point the purchaser needs any data about the item he can filter the QR code check by effective use of able to adapt application and afterward see the item subtleties in the able to be easily carried such pressing date, as assembling date , maker and wholesaler. Buyer should enroll himself in order to purchase the items from the wholesaler. The purchaser can then effectively check the item and they will purchase the item by utilizing on the web exchange. At long last client exchange ID and item name, cost will be added to the square chain.

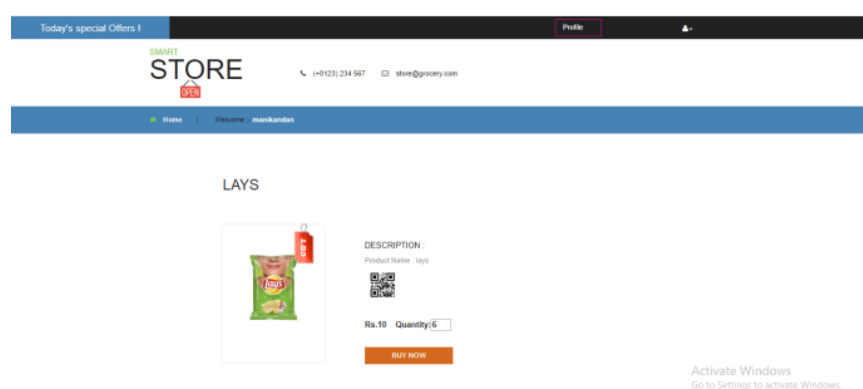

\section{RESULT AND DISCUSSION}

The calculation time of a solitary exchange generally will rely upon the hash calculation, the system inertness, and parallelization of a few calculation stages. Security is additionally a genuinely necessary element here which is all around gave by the utilization of block chain for putting away the information. The square chain structure is created by an open source coordinated advancement condition (IDE).
Along these lines the food items are observed and the vital subtleties are given as appeared in the accompanying figure. SHA-256 cryptographic hash work is utilized for hashing the source IP address, and the header hash, the RFID address .

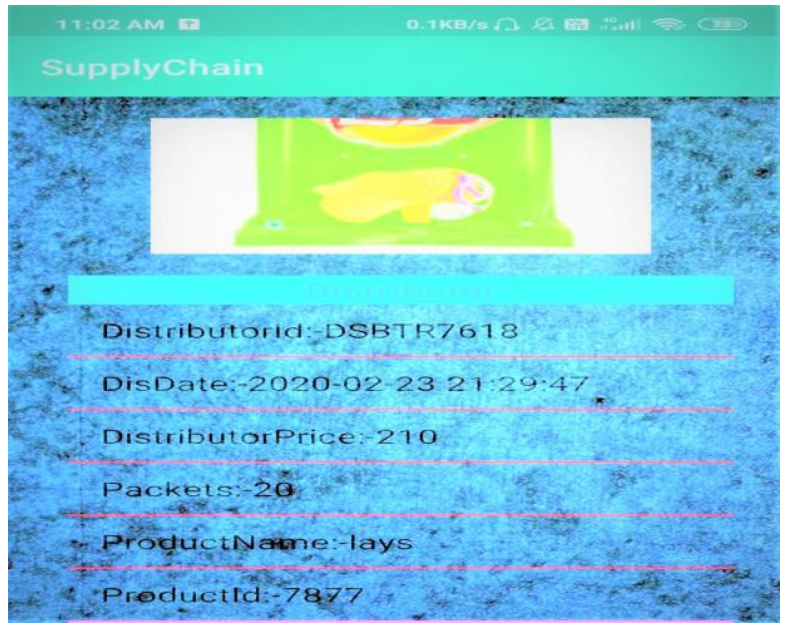

The real cost of the item is likewise determined and this can't be modified as these information gets put away in the square chain. From the producer square chain, the insights regarding the production ,the expiry date and the pressing date are acquired and are seen while examining the RFID tag.

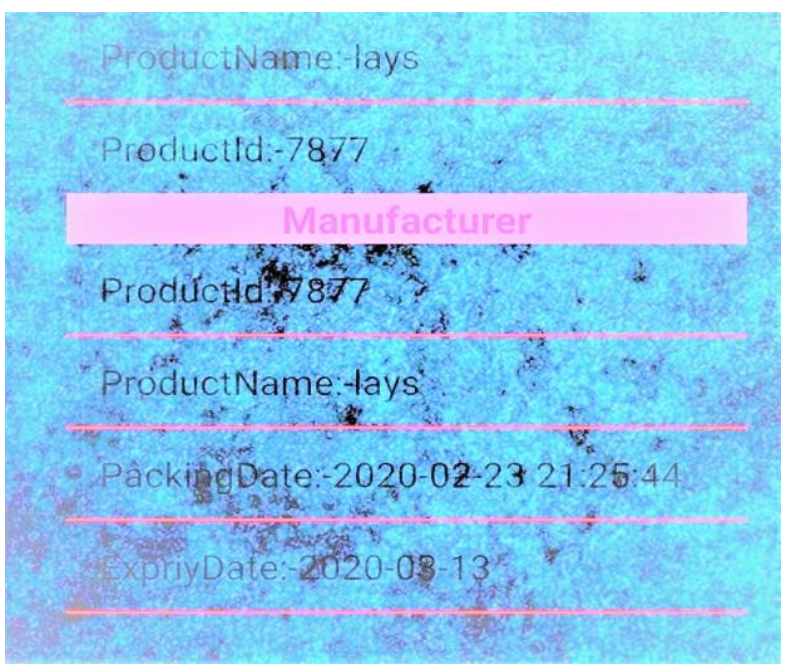

Here, it gives the whole insights concerning the merchant ,which incorporates wholesaler id, conveyed date and time, bundle subtleties and item id.

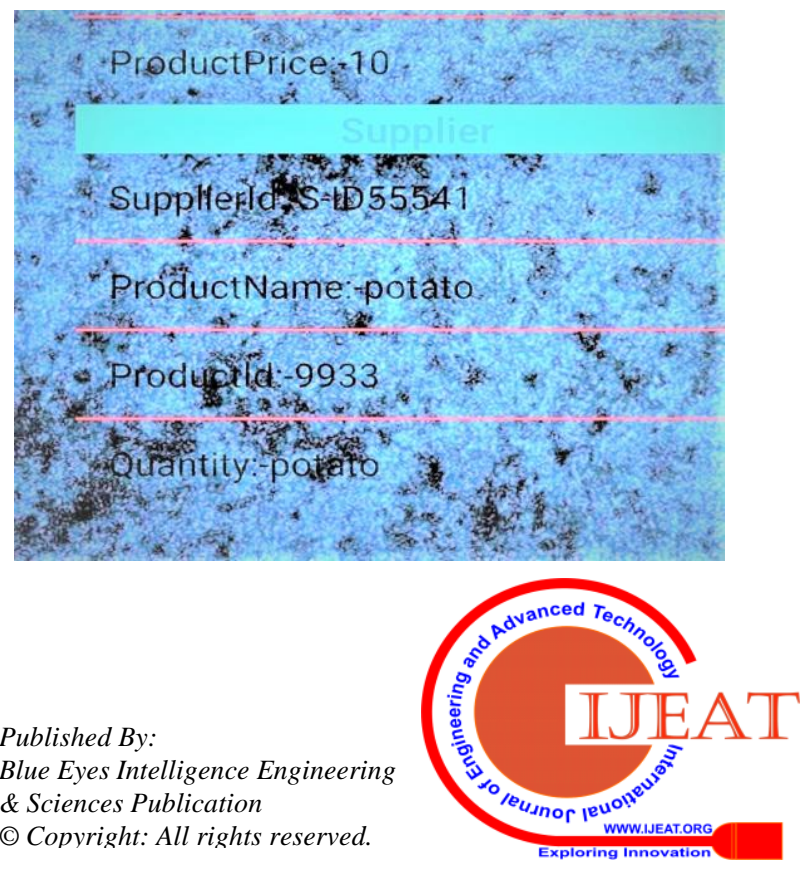


The provider subtleties are additionally object(an asset), agreement to do something(consent) and henceforth the copy items are totally maintained a overall aim distance from, while the clients are sheltered(protected from a) to purchase the items.

\section{CONCLUSION}

Our proposed framework is utilized(effect of use) to stay away from food polluting substance and make straightforward food flexibly chain. In this venture, RFID sensors is utilized at physical layer for constant quality checking. Subsequently Food wastage because of misguided judgment of mislabeled expiry dates, decay of food can be stayed away from.

\section{REFERENCE}

1. Things," in Proc. Int. Conf. Service Syst. Service Manag. (ICSSSM), 2017, PP. 1-6.

2. S. GUERON, S. JOHNSON, AND J. WALKER, "SHA-512/256," IN PROC. IEEE 8TH INT. CONF. INF. TECHNOL. NEW GENER.(ITNG), 2011, PP. 354-358.

3. X. LU,Z. QU, Q. LI,, AND P. HUI, "PRIVACY INFORMATION SECURITY CLASSIIICATION STUDY IN INTERNET OF THINGS,” INPROC. IEEE INT. CONF. IDENTIIICATION INF. KNOWL. INTERNET THINGS (IIKI), 2014, PP. 162-165

4. E. Smits et al., "Development of printed RFID sensor tags for smart food packaging," in Proc. 14th Int.

5. MeEting Chem. Sensors, Germany, Nuremberg 2012, PP. 20-23.

6. S. UNDERWOOD, "BLOCKCHAIN BEYOND BITCOIN," COMMUN. ACM, VOL. 59, NO. 11, PP. 15-17, 2016.

7. C. COSTA ET AL., "A REVIEW ON AGRI-FOOD SUPPLY CHAIN TRACEABILITY BY MEANS OF RFID TECHNOLOGY," FOOD

8. BIOPROCESS TECHNOL., VOL. 6, NO. 2, PP. 353-366, 2013.

9. S. HERSCHDOERFER, QUALITY CONTROL IN THE FOOD INDUSTRY, VOL 2. CAMBRIDGE, MA, USA: ELSEVIER, 2012.

10. W. Li, S. ANDreinA, G. Karame AND J.-M. Bohli "SECURING PROOF-OF-STAKE BLOCKCHAIN PROTOCOLS," IN DATA PRIVACY MANAGEMENT, CRYPTOCURRENCIES AND BLOCKCHAIN TECHNOLOGy. CHAM, SWITZERLAND: SPRINGER, 2017, PP. 297-315.

11. O. NOVO, "BLOCKCHAIN MEETS IOT: AN ARCHITECTURE FOR SCALABLE ACCESS MANAGEMENT IN IOT," IEEE INTERNET THINGS J., VOL. 5, NO. 2, PP. 1184-1195, APR. 2018.

12. F. TIAN, "A SUPPLY CHAIN TRACEABILITY SYSTEM FOR FOOD SAFETY BASED ON HACCP, BLOCKCHAIN \&AMP; INTERNET OF

\section{AUTHORS PROFILE}

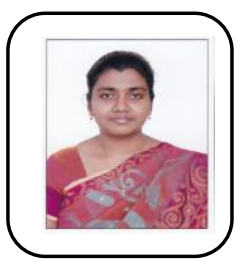

Ms.S.Sudha Mercy is currently working as Assistant Professor in the Department of Computer Science and Engineering at Jeppiaar Institute of Technology, kunnam. She completed her B.Tech (IT) at Anna University in 2011and Post Graduation M.E(CSE) at Anna University in 2013.She is currently pursuing Ph.D(CSE) at Anna University. She as 3.7 years of Teaching Experience. Her area of intrest include Wireless Sensor Networ, IOT, Data Structure and Design And Analysis of Algorithm.

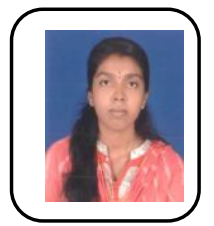

Abinaya $\mathbf{P}$ is currently pursuing his bachelor's degree in the stream of Computer Science and Engineering in Jeppiaar Institute of Technology, Kanchipuram, Tamil Nadu, India. She did her schooling in Erode. She Particularly interested in Blockchain, IOT, Sound knowledge in JAVA.

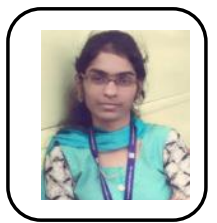

Kanimozhi J is currently pursuing his bachelor's degree in the stream of Computer Science and Engineering in Jeppiaar Institute of Technology , Kanchipuram, Tamil Nadu, India. She particularly interested in Web Development, Networking, and
Blockchain. Some of her non-academic interest include playing Baskeball ,Volleyball and Drawing.

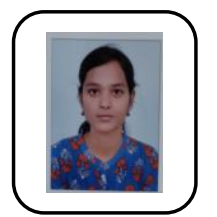

Shree Rohini I is currently pursuing his bachelor's degree in the stream of Computer Science and Engineering in Jeppiaar Institute of Technology , Kanchipuram, Tamil Nadu, India. She particularly interested in Database and Netwoing.

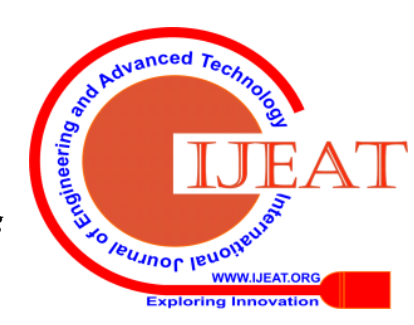

